J. Clin. Chem. Clin. Biochern.

Vol. 24, 1986, pp. 729-734

(C) 1986 Walter de Gruyter \& Co.

Berlin - New York

\title{
Neopterin and Interferon Gamma Serum Levels in Patients with Heart and Kidney Transplants
}

\author{
By W. Woloszczuk
}

Ludwig Boltzmann Institut für klinische Endokrinologie, Wien, Austria

\author{
M. Schwarz \\ II. Medizinische Universitätsklinik Wien, Austria \\ M. Havel, A. Laczkovics and M. M. Müller \\ II. Chirurgische Universitätsklinik Wien, Austria
}

(Received July 19, 1985/July 21, 1986)

Dedicated to Prof. Dr. E. Kaiser on his 60th birthday

Summary: The main problem in the follow-up of patients receiving organ allografts is the early differential diagnosis of rejection episodes and infections. Serum levels of interferon gamma, a marker of T-lymphocyte activity, were determined with an immunoradiometric assay, specific for biologically active interferon gamma and sufficiently sensitive $(20 \mathrm{U} / 1)$ for the determination of circulating interferon gamma. Neopterin, a pteridine released from stimulated macrophages, was determined by radioimmunoassay. Both rejection crises and infections are accompanied by distinct increases of serum neopterin (median values 124 and $128 \mathrm{nmol} / \mathrm{l}$; $\mathrm{N}=98$ ). Interferon gamma levels are elevated for a short period one or two days earlier, the maximal values during infections (median $430 \mathrm{U} / 1$, range $120=1220 \mathrm{U} / \mathrm{l}, \mathrm{N}=25$ ) being higher than those during rejection episodes (median $120 \mathrm{U} / 1$, range $<20-330 \mathrm{U} / 1, \mathrm{~N}=73$ ). Each rise of interferon gamma was followed by an increase of neopterin, but nôt every neopterin increase was preçeded by a interferon gamma peak. Neither of these parameters showed an increase during deterioration of kidney function due to cyclosporin toxicity. The determination of interferon gamma, a lymphokine involved in the activation of alloreactivity, reflecting T-cell stimulation, and the measurement of neopterin, a secretory product of activated macrophages, allows the simple, quick and reliable monitoring of the immune status of transplant recipients.

\section{Konzentrationen von Neopterin und $\gamma=$ Interferon im Serum bei Patienten mit Herz- und Nierentransplantaten}

Zusammenfạssuiung: Wesentliche Probleme bei der Nachșorge allotransplantierter Patienten liegen in der rechtzeitigen Diagnose von Abstoßungsreaktionen und Infektionen. Die Konzentration von $\gamma$-Interferon, einem Indikator der Aktivität von T-Lymphocyten, wurde in einem hochsensitiven, für biologisch aktives $\gamma$ Interferon spezifischen immunoradiometrischen Test, der ausreichend empfindlich zur Messung von zirkulierendem $\gamma$-Interferon ist, bestimmt. Neopterin, ein von aktivierten Makrophagen produziertes Pteridin, wurde mittels Radioimmunoassays bestimmt. Sowohl akute Abstoßungsreaktionen als auch Infektionen waren von deutlichen Erhöhungen des Neopterin im Serum begleitet (Mediane 124 und $128 \mathrm{nmol} / \mathrm{l} ; \mathrm{N}=98$ ). $\gamma$ Interferon-Konzentrationen waren kurzfristig ein bis zwei Tage früher erhöht, wobei die Maximalwerte bei Infektionen (Median $430 \mathrm{U} / \mathrm{l}$, Bereich $120-1220 \mathrm{U} / \mathrm{h}, \mathrm{N}=25$ ) höher waren als bei Abstoßungsreaktionen (Median $120 \mathrm{U} / \mathrm{l}$, Bereich < 20-330 U/1, N = 73). Jedem $\gamma$-Interferon-Anstieg folgte eine merkliche Neopte- 
rin-Erhöhung, aber nicht jedem Neopterin-Anstieg ging eine entsprechende $\gamma$-Interferon-Erhöhung voraus. Keine dieser Kenngrößen war bei Cyclosporin-A bedingter Verschlechterung der Nierenfunktion erhöht. Die Bestimmung von $\gamma$-Interferon, einem Lymphokin, das bei der Alloreaktivitätsaktivierung beteiligt ist und damit ein Maß für den Grad der T-Zell-Stimulation darstellt, und Neopterin, welches die Aktivität der Makrophagen angibt, ermöglicht die einfache, rasche und verläßliche Beurteilung des Immunstatus von Transplantatempfängern.

\section{Introduction}

Immunological monitoring of patients with heart or kidney allografts is decisive for the proper treatment of possible complications. Despite significant improvements in the clinical management of transplant recipients, with reduction of the corticosteroid dosage and immunosuppression with cyclosporin A, differential diagnosis of infections and rejections still poses a major problem. This distinction is especially critical, because the necessary subsequent changes in the immunosuppressive regimen are different, depending on the diagnosis. It has been shown that low excretion of neopterin in urine is a reliable indicator for the absence of immunological stimuli, whereas high excretion is found during rejection episodes and infections (1). In vitro interferon gamma, a lymphokine secreted by activated $\mathrm{T}$-cells, stimulates the release of neopterin from macrophages (2). We report here the results of measurements in patient sera of interferon gamma and neopterin, and demonstrate that a similar regulatory pattern does exist in vivo. The routine determinations of neopterin and interferon gamma seem to be of high relevance for the daily monitoring of transplant recipients.

\section{Methods}

Interferon gamma was determined using a modified version of a commercially available immunoradiometric assay (3). In this 2-step "sandwich" test interferon gamma present in the sample is first bound to a monoclonal antibody coated onto a polystyrene bead. In the second step, the bound interferon gamma in turn binds to another monoclonal antibody, labelled with iodine-125. One of the two antibodies is specific for the active structure, thus measuring only biologically active interferon gamma with a sensitivity of $20 \mathrm{U} / 1$.

Neopterin in serum was determined with a radioimmunosassay (Henning, Berlin, FRG; (4)), modified to adapt its working range to the elevated levels expected in transplant patients: The sample volume was reduced from $50 \mu 1$ to $20 \mu \mathrm{l}$ and an additional standard $(320 \mathrm{nmol} / \mathrm{l})$ was used for the construction of the standard curve. The incubation and separation steps were as recommended in the instructions for use.

\section{Patients}

In six patients with heart transplants, serum levels of interferon gamma and neopterin were determined throughout the early postoperative period of at least 5 weeks. In 63 patients with kidney transplants (age 18-62 years), serum levels of neopterin were determined daily. The main reasons for kidney failure were chronic glomerulonephritis, chronic pyelonephritis, polycystic kidney disease and interstitial nephritis. In 28 of these patients interferon gamma was measured daily. Six heart recipients (age $10-40$ years) were transplanted due to cardiomyopathy, coronary heart disease or intractably reduced ventricle function. Sample collection started on the day of transplantation and was continued until discharge from the unit. The immunosuppressive therapy consisted of cyclosporin $\mathrm{A}$ and prednisolone in the majority of kidney patients, whereas according to the standard protocol all the heart patients received azathioprine and anti-thymocyte globulin. In rejection cases, pulse therapy with high-dose methylprednisolone and repeated anti-thymocyte globulin was performed (tab. 1). Diagnosis of rejection in kidney recipients was based on clinical symptoms, laboratory findings, blood chemistry, sonography and the 111-Indiumlabelled platelet uptake index. In heart transplant patients diagnosis of rejection was based mainly on endomyocardial biopsy (5), whereas other methods such as echocardiography and ECG were not of decisive importance. Heart biopsies were taken weekly, in cases of clinical impairment and after treatment by steroid pulse therapy. In kidney patients, biopsies were taken if necessary and analysed cytologically (fine needle aspiration biopsy) or histologically (tru-cut biopsy). 99m-Technetium bolus investigation, computerized tomography, and digital subtraction angiography were performed, as appropriate. The diagnosis of complicating infections was based on repeated bacteriological and serological tests such as blood cultures, complement binding reaction, IgM- and IgG-titers, and virus isolation in addition to clinical.symptoms.

Changes in serum neopterin were evaluated statistically, using Student's t-difference test. Since data were not normally distributed, median values and ranges are given. Differences between groups were calculated using a non-parametric test.

\section{Results}

Serum neopterin levels were significantly different depending upon the clinical course after transplantation (fig. 1). Thirty five kidney graft recipients without infections were classified into 3 . groups according to their clinical course. All were treated only with cyclosporin $\mathrm{A}$ and steroids and/or anti-thymocyte globulin (tab. 1), and none of these patients suffered from severe infections that might have influenced serum neopterin levels or required modifications in the immunsuppressive management during the early postoperative period of up to 5 weeks.

Group I comprised 8 patients free of immunological complications, and therefore without additional immunosuppressive therapy. Neopterin decreased ra- 
Tab. 1. Details and dosage of immunosuppressive therapy.

\begin{tabular}{|c|c|c|}
\hline Protocol & Kidney grafts & Heart grafts \\
\hline \multicolumn{3}{|l|}{ Standard } \\
\hline Before transplantation & Cyclosporin A $5 \mathrm{mg} / \mathrm{kg}$ bw iv & $\begin{array}{l}\text { Cyclosporin A } 15 \mathrm{mg} / \mathrm{kg} \text { bw iv } \\
\text { Azathioprin } 4 \mathrm{mg} / \mathrm{kg} \text { bw iv }\end{array}$ \\
\hline During transplantation & Methylprednisolone $200 \mathrm{mg}$ iv & Methylprednisolone $500 \mathrm{mg}$ iv \\
\hline After transplantation & $\begin{array}{l}\text { Cyclosporin A } 5 \mathrm{mg} / \mathrm{kg} \text { bw iv ( } 3 \text { days) } \\
\text { Cyclosporin A po (*) } \\
\text { Methylprednisolone tapered down to } 20 \mathrm{mg}\end{array}$ & $\begin{array}{l}\text { Cyclosporin A } 9 \mathrm{mg} / \mathrm{kg} \text { bw po }\left(^{*}\right) \\
\text { Methylprednisolone } 3 \times 125 \mathrm{mg} \text { iv } \\
\text { Azathioprin } 2 \mathrm{mg} / \mathrm{kg} \mathrm{bw} \mathrm{iv}(* *) \\
\text { Anti-thymocyte globulin } 10 \mathrm{mg} / \mathrm{kg} \text { bw iv }\end{array}$ \\
\hline \multicolumn{3}{|l|}{ Rejection } \\
\hline & $\begin{array}{l}\text { Methylprednisolone } 500 \mathrm{mg} \text { ( } 3 \text { days) or } \\
\text { Anti-thymocyte globulin } 3 \mathrm{mg} / \mathrm{kg} \text { bw (10 days) or } \\
\text { plasmapheresis }\end{array}$ & $\begin{array}{l}\text { Methylprednisolone } 1000 \mathrm{mg} \text { ( } 3 \text { days) or } \\
\text { Anti-thymocyte globulin } 10 \mathrm{mg} / \mathrm{kg} \text { bw (10 days) }\end{array}$ \\
\hline
\end{tabular}

(*) ... dosage adjusted according to blood levels

(**) ... dosage corrected according to cell count

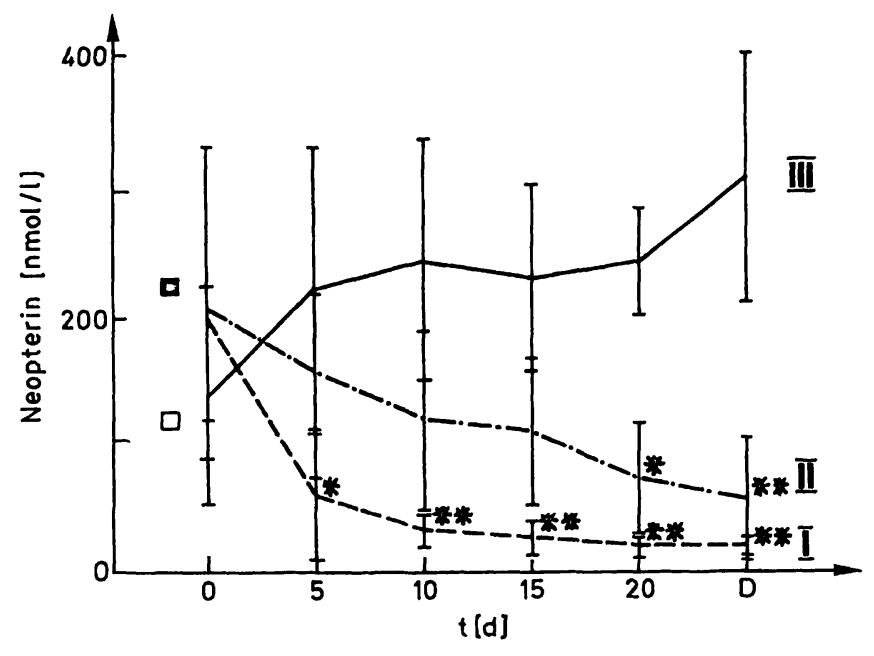

Fig. 1. Time course of neopterin in serum of 35 patients after kidney transplantation (mean values and standard deviations).

Group I $(\mathrm{N}=8) \ldots$ no complications

Group II $(\mathrm{N}=22) \ldots$ reversible rejections

Group III $(\mathrm{N}=5) \ldots$ graft loss due to irreversible rejection

Significant differences from pretreatment levels are indicated $(*<\mathrm{p} 0.05 ; * *<0.01)$.

D ... day of discharge (groups I \& II) or graft loss (group III). Average levels of neopterin in serum in patients on haemodialysis before (a) and after ( $\square$ ) dialysis (see fig. 3).

pidly to levels only slightly higher than those of healthy normal controls $(\mathrm{N}=25)$.

Twenty two patients (group II) had rejection episodes diagnosed by clinical symptoms or transplant biopsy that were reversible by appropriate therapy. A decrease of neopterin values was also observed, but was delayed in comparison with group $I$. On the day of discharge, neopterin levels were slightly, but not significantly higher than for group I.
Group III comprises the five patients that lost their transplants due to irreversible rejection. The highest neopterin values were found on the day before graft loss. Figure 2 shows similar, but individual data for

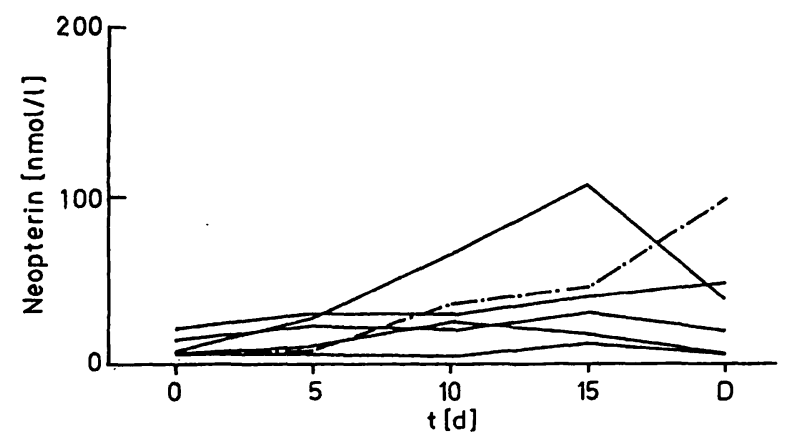

Fig. 2. Individual time courses of serum neopterin in 6 patients after heart transplantation. One patient (-.-.-.-) died of acute rejection.

D...day of discharge or graft loss.

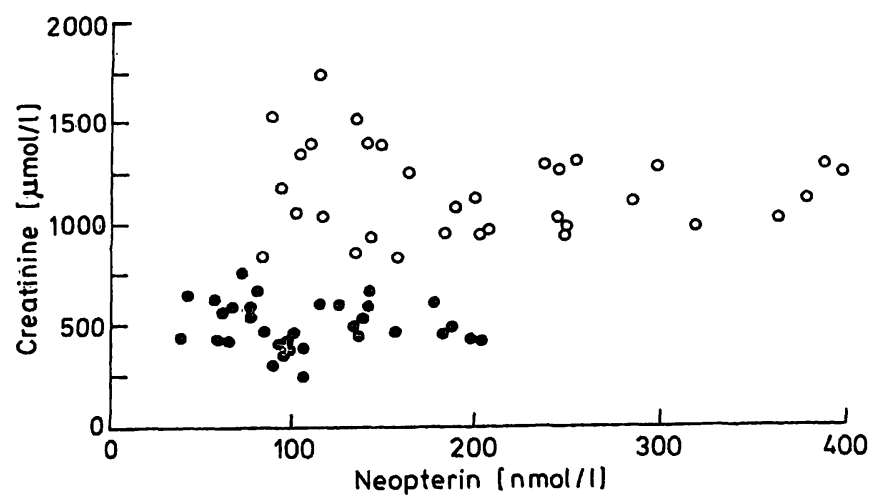

Fig. 3. Neopterin and creatinine serum concentrations before (0) and after (0) haemodialysis (5-6 hours) in 33 patients with no apparent immunological activity. 
six heart transplant patients. To interpret the pretransplant levels of neopterin in serum, values for patients with chronic renal failure and the effects of haemodialysis are shown in figure 3. After dialysis, concentrations of neopterin were decreased by about
$50 \%$, but they were still 5-fold higher than normal controls. No quantitative correlation between the reduction by haemodialysis of serum neopterin and creatinine, blood urea nitrogen or uric acid was found.
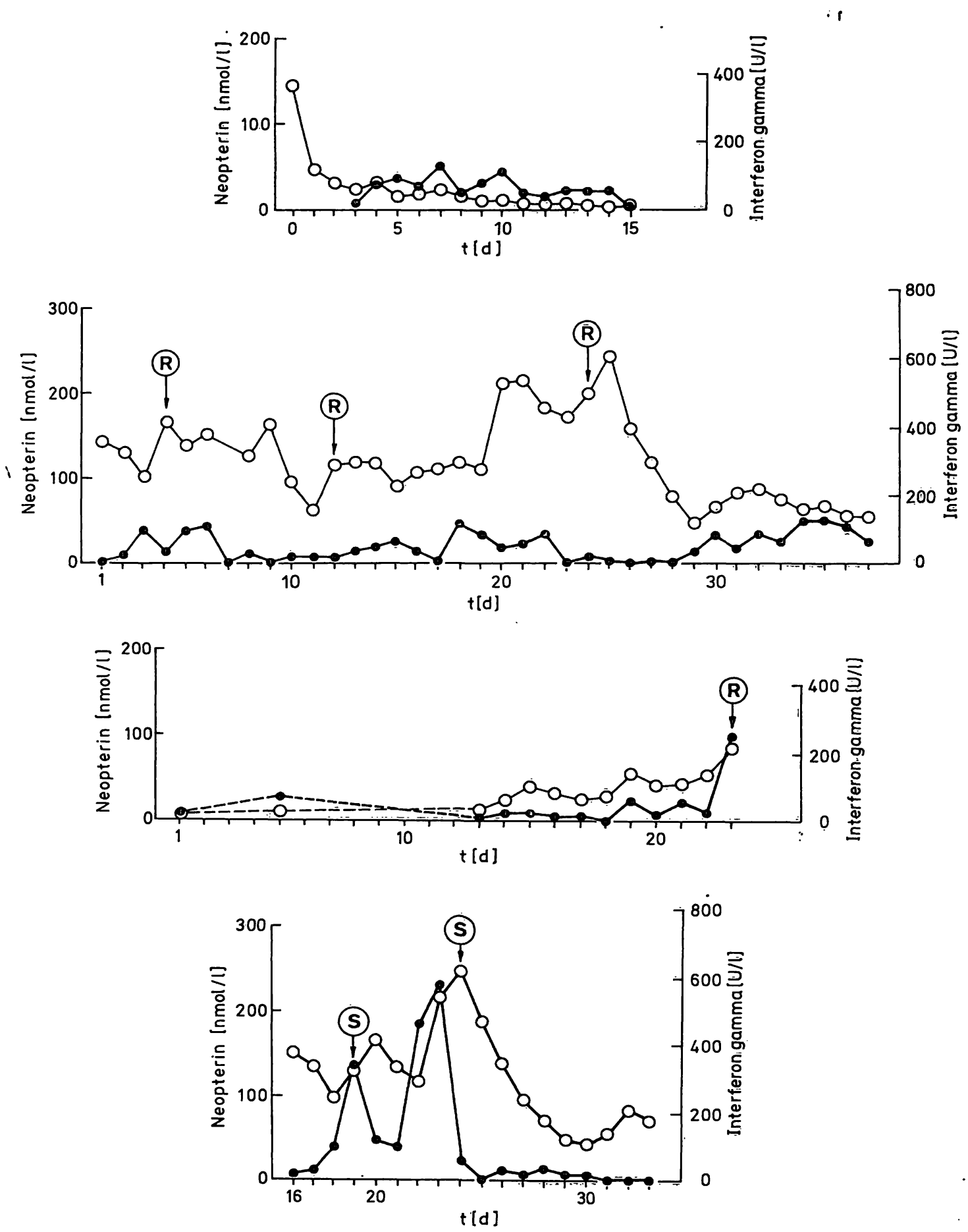

Fig. 4. Time course of interferon gamma $(\bullet)$ and neopterin $(0)$ serum levels.

a) Patient with kidney graft; uncomplicated clinical course. Low interferon gamma and neopterin quickly decreasing after transplantation.

b) Patient with kidney graft; several reversible rejection episodes ß. Only slight elevations in interferon gamma büt marked increases of neopterin at time of symptoms or biopsy (the last rejection episode was pröven histologically). Decrease of neopterin levels with clinical improvement due to therapy.

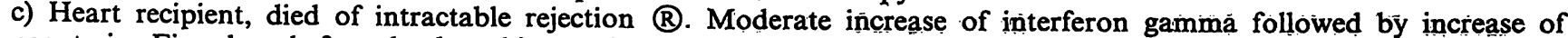
neopterin. Five days before death, a biopsy showed no signs of rejection, and interferon gamma as well as neopterin levels were low.

d) Patient with kidney graft; septic complications, proven by repeated positive bacterial blood cultures (S)

Pronounced interferon gamma peaks in contrast to rejection episodes. 
Tab. 2. Interferon gamma and neopterin serum levels. Values in 25 healthy controls, 65 kidney and 6 heart recipients with 73 rejection episodes and 25 infections. Values given are median and range.

\begin{tabular}{lll}
\hline & $\begin{array}{l}\text { Interferon gamma } \\
(\mathrm{U} / \mathrm{l})\end{array}$ & $\begin{array}{l}\text { Neopterin } \\
(\mathrm{nmol} / \mathrm{l})\end{array}$ \\
\hline $\begin{array}{l}\text { Acute rejections } \\
\text { day of diagnosis }\end{array}$ & $120($ n.d. -330$)(1,2)$ & $124(39-495)(1)$ \\
2 days later & $80($ n.d. -150$)(1,3)$ & $121(48-560)(1)$ \\
$\begin{array}{l}\text { Infections } \\
\text { day of diagnosis }\end{array}$ & $430(120-1220)(1)$ & $62(23-129)(1)$ \\
2 days later & $160($ n.d. -470$)(1,4)$ & $128(46-520)(1,5)$ \\
& range n.d. -35 & $5(0.4-10.2)$ \\
\hline
\end{tabular}

n.d. ... not detectable $(<20 \mathrm{U} / \mathrm{l})$

(1) ... higher than normal controls $(p<0.01)$

(2) ... lower than at the day of diagnosis of infection $(p<0.01)$

(3) $\ldots$ lower than 2 days earlier $(p<0.05)$

(4) ... lower than 2 days earlier $(p<0.01)$

(5) ... higher than 2 days earlier $(p<0.02)$

Data from patients with rejections and infectious complications are summarized in table 2 . In all patients with severe infection episodes (viral, $\mathrm{N}=8$, and bacterial, $\mathrm{N}=17$ ) distinct peaks of interferon gamma were observed, followed 1 to 2 days later by marked increases of neopterin. In contrast, less pronounced or unmeasurable increments of interferon gamma were seen during acute rejection episodes, whereas neopterin peak levels were as high as those during infections. To illustrate the relation between neopterin and interferon gamma in serum, four cases are shown in figures $4 a-d$ (details are given in the legends).

\section{Discussion}

The clinical value of daily measurements of neopterin excretion in urine has been demonstrated in kidney transplantations and other clinical situations (1). Recently, it has been shown that the neopterin is released by macrophages when they are stimulated by interferon gamma produced from activated T-lymphocytes (2). These in vitro results have prompted us to investigate the use of serum neopterin for the monitoring of transplant patients and to search for a similar regulatory pattern in vivo. Case reports have been published (5) in which measurable interferon gamma levels in serum were found associated with stimulations of the immune system, both during infections and in some but not all rejection crises. A clinically uncomplicated posttransplant course was almost invariably associated with rapidly decreasing neopterin levels in kidney patients and with stable and low levels for heart recipients. This dissimilarity is probably the consequence of different pretransplant levels. Patients on haemodialysis have neopterin values much higher than normal controls even without any apparent immunological stimuli, reflecting the predominantly renal excretion of pteridines. The onset of acute rejection episodes were in all cases associated with rising neopterin levels or, in the case of some kidney recipients, with delay or cessation of the decline expected for an immunologically uncomplicated course. The relative small increase of neopterin in the heart patient with an irreversible rejection is probably due to the early end of function of this vital organ, which contrasts with rejection episodes in kidney recipients that are not of immediate danger to life. Interferon gamma was clearly elevated for a short period at the onset of infections, but only to a lower extent during rejection crises. It thus appears that the daily monitoring of interferon gamma and neopterin levels in serum are useful for the detection of immunological activations. Similarly, urinary neopterin excretion has been shown to allow the early diagnosis of acute rejections and viral infections with very few false positive results (1).

With the development of a quick and reliable assay sufficiently sensitive to detect interferon gamma in peripheral blood, it is now possible to determine a lymphokine that controls the activation of macrophages. This offers an additional advantage, since elevations of interferon gamma preceeded the neopterin increases by one or two days, as expected from in vitro experiments. Without exception, every increase of interferon gamma over $120 \mathrm{U} / 1$ was followed by a significant rise in neopterin. From a practical point of view its determination in serum seems to be at least as useful as the determination of the urinary excretion, with the additional advantage of being independent of urine output. Furthermore, interferon gamma might help in the differential diagnosis of rejection and infection, since the majority of infections showed peak levels above the maximal values measured during acute rejections.

In conclusion, the simultaneous daily determination of interferon gamma and neopterin in the early postoperative period seems to be a useful tool for differential diagnosis of immunological complications and for monitoring their treatment in kidney and heart transplant patients.

\section{Acknowledgement}

The authors thank Mrs. Malgorzata Horzemski for her expert technical help. 


\section{References}

1. Margreiter, R., Fuchs, D., Hausen, A., Huber, Ch., Reibnegger, G., Spielberg, M. \& Wachter, H. (1983) Transplantation 36, 650-653.

2. Huber, Ch., Batchelor, J. R., Fuchs, D., Hausen, A., Lang, A., Niederwieser, D., Reibnegger, G., Swetly, P., Troppmair, J. \& Wachter, H. (1984) J. Exp. Med. 160, 310-316.

3. Woloszczuk, W. (1985) Clin. Chem. 31, 1090.

4. Rokos, K., Rokos, H. \& Frisius, H. (1982) In: Biochemical and Clinical Aspects of Pteridines (Wachter, H., Curtius, $H$. Ch. \& Pfleiderer, W., eds.) Walter de Gruyter, Berlin-New York, Vol. I, pp. 117-130.

5. Billingham, M., Warnke, R. \& Weissman, I. (1977) Transplantation 23, $171-175$.

6. Woloszczuk, W., Kovarik, J., Schwarż, M., Pohanka, E. \& Mayer, G. (1985) In: Biochemical and Clinical Aspects of Pteridines (Wachter, H., Curtius, H. Ch. \& Pfleiderer, W., eds.) Walter de Gruyter, Berlin - New York, Völ. IV, pp. $429-439$.

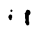

Dr. W. Woloszczuk Ludwig Boltzmann Institut für Klinische Endokrinologie 2. Medizinische Universitätsklinik Garnisongasse 13

A-1090 Wien 